\title{
APPLICATION OF FILTEK SILORANE-INITIAL OBSERVATIONS AND PROSPECTIVE CLINICAL TRIAL FOR 12 MONTHS
}

\author{
Lyubomir Vangelov*, Kremena Markova*, Tsonka Miteva**, \\ * Department of operative dentistry and endodontics, Faculty of Dental \\ Medicine, Medical University, Plovdiv, Bulgaria, \\ ** Department of social medicine and public health, Faculty of Medicine, \\ Medical University, Plovdiv, Bulgaria,
}

\section{SUMMERY:}

Polymerization shrinkage and related adverse effects are still considered a major problem of dental composites. To solve this problem different approaches are offered. Currently, 3M ESPE developed a new monomer system based on cationic ring opening, the goal is to create a composite material with low polymerization shrinкаge called siloran. Aim: To investigate the clinical presentation of Filtek ${ }^{\mathrm{TM}}$ Silorane Low Shrink Posterior Restorative for an observation period of 12 months. Material and methods: The study included 36 patients. Total of 66 restorations are made. They were evaluated using modified USPHS criteria of Ryge and Cvar. After their assessment, restorations were captured with a digital camera and X-rays were taken in parallel technique. On control examination after one year, 31 patients (63 restorations) were available for the study. Same parameters were assessed and new digital pictures and X-rays were made. The statistics was made with software SPSS version 17 . For statistical analysis a Criterion Pirson $(\chi 2)$ was used. Results: With the exception of one of the criteria, it was shown that no statistically significant difference exists between the baseline and after one year $(p>0,05)$. Only the criterion surface of the filling was found to have statistically significant difference $(\mathrm{p}<0,05)$ class two

Key words: Filtek Silorane, clinical study, composite,

\section{INTRODUCTION:}

Polymerization shrinkage and related adverse effects are still considered a major problem of dental composites. This is particularly true in obturation of the distal segments of the dentition, where cracks, marginal staining, postoperative sensitivity and secondary caries appear ${ }^{1}$.

Different approaches are offered to solve this problem:

- Incorporating new components: a glass-alkaline filler particles eradiating functional ions (calcium fluoride) to inhibit bacterial activity and reduce demineralization ${ }^{2}$, silver ions with antimicrobial activity ${ }^{3}$. However, this approach is not designed to cope with the contraction itself,and the consequences thereof.

- Reducing the size of filler particles to $0,005 \div 0,01$ $\mathrm{Mm}$ in nanofiled composites, increasing the percentage of filler particles, especially in condensible composites ${ }^{4}$.

- Incorporation of the glass fibers in the composition of composites, the introduction of ormocer technology ${ }^{5}$.

- Introduction of the Spiro-ortho-carbonate (SOC) materials, that can withstand cationic polymerization with volume expansion.

Until now the main strategies for dealing with the problem are to reduce the amount of the resin (bis-GMA, UDMA, BPDM, etc.). by reducing the size of inorganic particles and increasing the filler load ${ }^{6}$. Polymerization shrinkage is an immanance of the dimetacrylates used to this day as an organic matrix. Regardless of reducing them, the problem of shrinking remains. The application of organic matrix of different chemical nature seems most logical way to tackle this problem.

Currently, 3M ESPE developed a new monomer system based on cationic ring opening, the goal is to create a composite material with low polymerization shrinкаge-called siloran $^{6,7}$. As a commercial product based on this structure, on the market appeared Filtek ${ }^{\mathrm{TM}}$ Silorane Low Shrink Posterior Restorative - first posterior composite material with less than $1 \%$ shrinkage on polymerization according to the manufacturer. This is material which is more experimental and laboratory researched and there are very few publications on the clinical behavior ${ }^{8}$.

\section{AIM:}

To investigate the clinical presentation of Filtek д Silorane Low Shrink Posterior Restorative for an observation period of 12 months.

\section{MATERIAL AND METHODS:}

The study included 36 patients. They are informed about the nature of the study and signed informed consent. Each of them receieved at least one obturation with Filtek 
Silorane. Total of 66 restorations are made. Selected cases met the following criteria:

second class, primary or secondary carious lesions with gingival base located next to or above the cement-enamel border (detectable by diagnostic X-ray or during preparation), the presence of adjacent teeth for restoration of contact points, and antagonists.

To restore contact with adjacent teeth we used Palodent sectional Matrix System-Darway, Inc. and rings BiTine-Dentsply Caulc. For polymerization we used light curing unit "Bluedent LED Smart" - D\&A Electronics Ltd, Bulgaria. Color selection was made before preparation, while the tooth is still hydrated. In the preparation of the cavities, minimally invasive, adhesive approach was used. Where necessary, caries detector (Sable seek-Ultradent, Inc USA) was. used. After isolation of the operative field, cavity was flushed with chlorhexidine and dryed.

The application of the adhesive system was according to manufacturer's instructions.

It contains two bottles self-etch primer and bond. It should be noted that due to its different chemistry this adhesive system is incompatible with "traditional" composite materials with organic matrix of methacrylate type.

During obturation of the cavities the centripetal technique (Bichacho 1994) was used. Each layer was applied with a thickness of no more than $2.5 \mathrm{~mm}$ and then cured for 40 seconds. Finishing and polishing were done with discs, brushes and polish paste.

Restorations were evaluated using modified USPHS criteria of Ryge and Cvar. Monitoring parameters are: colour, discoloration on the composite-enamel border, anatomic form, marginal adaptation, surface finishing, secondary caries, contact point, changes in interdental papilla. Evaluation was done by two clinicians not involved in the study. In case of disagreement, the evaluators discussed it to find consensus . After their assessment, restorations were captured with a digital camera and $\mathrm{X}$-rays were taken in parallel technique.

On control examination after one year, 31 patients (63 restorations) were available for the study. Same parameters were assessed and new digital pictures and X-rays were made.

The statistics was made with software SPSS version 17. For statistical analysis a Criterion Pirson $(\chi 2)$ was used. The working hypothesis for each of the parameters verified is that there was significant difference in the evaluations made during the observation period.

\section{RESULTS:}

With the exception of one of the criteria, it was shown that no statistically significant difference exists between the baseline and after one year ( $p>0,05)$.

\begin{tabular}{|c|c|c|c|c|c|c|c|c|c|c|c|c|c|c|}
\hline \multirow{3}{*}{ Time } & \multicolumn{14}{|c|}{ "colour" } \\
\hline & \multicolumn{3}{|c|}{ oscar } & \multicolumn{3}{|c|}{ alfa } & \multicolumn{3}{|c|}{ bravo } & \multicolumn{3}{|c|}{ charlie } & \multicolumn{2}{|c|}{ Total } \\
\hline & $\mathrm{N}$ & $\mathrm{P} \%$ & Sp \% & $\mathrm{N}$ & P \% & Sp \% & $\mathrm{N}$ & $\mathrm{P} \%$ & $\mathrm{Sp} \%$ & $\mathrm{~N}$ & P \% & Sp \% & $\mathrm{N}$ & $\mathrm{P} \%$ \\
\hline baseline & 50 & 75,76 & 43,3 & 16 & 24,24 & 42,85 & 0 & 0,00 & 0,00 & 0 & 0,00 & 0,00 & 66 & 100 \\
\hline 12 month & 41 & 65,08 & 14,7 & 22 & 34,92 & 47,67 & 0 & 0,00 & 0,00 & 0 & 0,00 & 0,00 & 63 & 100 \\
\hline
\end{tabular}

$\chi 2=4,86 \mathrm{p}>0,05$

\begin{tabular}{|c|c|c|c|c|c|c|c|c|c|c|c|}
\hline \multirow{3}{*}{ Time } & \multicolumn{11}{|c|}{ discoloration on the composite-enamel border } \\
\hline & \multicolumn{3}{|c|}{ alfa } & \multicolumn{3}{|c|}{ bravo } & \multicolumn{3}{|c|}{ charlie } & \multicolumn{2}{|c|}{ Total } \\
\hline & $\mathrm{N}$ & $\mathrm{P} \%$ & $\mathrm{Sp} \%$ & $\mathrm{~N}$ & $\mathrm{P} \%$ & $\mathrm{Sp} \%$ & $\mathrm{~N}$ & $\mathrm{P} \%$ & $\mathrm{Sp} \%$ & $\mathrm{~N}$ & $\mathrm{P} \%$ \\
\hline baseline & 66 & 100,00 & 0,00 & 0 & 0,00 & 0,00 & 0 & 0,00 & 0,00 & 66 & 100 \\
\hline 12 month & 62 & 98,41 & 12,50 & 1 & 1,59 & 12,50 & 0 & 0,00 & 0,00 & 63 & 100 \\
\hline
\end{tabular}

$\chi 2=2,19 \mathrm{p}>0,05$

\begin{tabular}{|c|c|c|c|c|c|c|c|c|c|c|c|}
\hline \multirow{3}{*}{ Time } & \multicolumn{11}{|c|}{ anatomic form } \\
\hline & \multicolumn{3}{|c|}{ alfa } & \multicolumn{3}{|c|}{ bravo } & \multicolumn{3}{|c|}{ charlie } & \multicolumn{2}{|c|}{ Total } \\
\hline & $\mathrm{N}$ & P \% & $\mathrm{Sp} \%$ & $\mathrm{~N}$ & $\mathrm{P} \%$ & $\mathrm{Sp} \%$ & $\mathrm{~N}$ & $\mathrm{P} \%$ & Sp \% & $\mathrm{N}$ & $\mathrm{P} \%$ \\
\hline baseline & 63 & 95,45 & 20,83 & 3 & 4,55 & 20,83 & 0 & 0,00 & 0,00 & 66 & 100 \\
\hline 12 month & 60 & 95,24 & 21,30 & 3 & 4,76 & 21,30 & 0 & 0,00 & 0,00 & 63 & 100 \\
\hline
\end{tabular}

$$
\chi 2=0,01 \quad \mathrm{p}>0,05
$$




\begin{tabular}{|c|c|c|c|c|c|c|c|c|c|c|c|}
\hline \multirow{3}{*}{ Time } & \multicolumn{11}{|c|}{ marginal adaptation } \\
\hline & \multicolumn{3}{|c|}{ alfa } & \multicolumn{3}{|c|}{ bravo } & \multicolumn{3}{|c|}{ charlie } & \multicolumn{2}{|c|}{ Total } \\
\hline & $\mathrm{N}$ & $\mathrm{P} \%$ & $\mathrm{Sp} \%$ & $\mathrm{~N}$ & $\mathrm{P} \%$ & $\mathrm{Sp} \%$ & $\mathrm{~N}$ & $\mathrm{P} \%$ & $\mathrm{Sp} \%$ & $\mathrm{~N}$ & $\mathrm{P} \%$ \\
\hline baseline & 66 & 100,00 & 0,00 & 0 & 0,00 & 0,00 & 0 & 0,00 & 0,00 & 66 & 100 \\
\hline 12 month & 60 & 95,24 & 21,30 & 3 & 4,76 & 21,30 & 0 & 0,00 & 0,00 & 63 & 100 \\
\hline
\end{tabular}

$$
\chi 2=3,3 \mathrm{p}<0,05
$$

\begin{tabular}{|c|c|c|c|c|c|c|c|c|c|c|c|}
\hline \multirow{3}{*}{ Time } & \multicolumn{11}{|c|}{ surface finishing } \\
\hline & \multicolumn{3}{|c|}{ alfa } & \multicolumn{3}{|c|}{ bravo } & \multicolumn{3}{|c|}{ charlie } & \multicolumn{2}{|c|}{ Total } \\
\hline & $\mathrm{N}$ & $\mathrm{P} \%$ & $\mathrm{Sp} \%$ & $\mathrm{~N}$ & $\mathrm{P} \%$ & $\mathrm{Sp} \%$ & $\mathrm{~N}$ & $\mathrm{P} \%$ & $\mathrm{Sp} \%$ & $\mathrm{~N}$ & $\mathrm{P} \%$ \\
\hline baseline & 66 & 100,00 & 0,00 & 0 & 0,00 & 0,00 & 0 & 0,00 & 0,00 & 66 & 100 \\
\hline 12 month & 57 & 90,48 & 29,35 & 6 & 9,52 & 29,35 & 0 & 0,00 & 0,00 & 63 & 100 \\
\hline
\end{tabular}

$$
\chi 2=4,86 \mathrm{p}<0,05
$$

\begin{tabular}{|c|c|c|c|c|c|c|c|c|c|c|c|}
\hline \multirow{3}{*}{ Time } & \multicolumn{11}{|c|}{ secondary caries } \\
\hline & \multicolumn{3}{|c|}{ alfa } & \multicolumn{3}{|c|}{ bravo } & \multicolumn{3}{|c|}{ charlie } & \multicolumn{2}{|c|}{ Total } \\
\hline & $\mathrm{N}($ & $\mathrm{P} \%$ & $\mathrm{Sp} \%$ & $\mathrm{~N}$ & $\mathrm{P} \%$ & $\mathrm{Sp} \%$ & $\mathrm{~N}$ & $\mathrm{P} \%$ & $\mathrm{Sp} \%$ & $\mathrm{~N}$ & $\mathrm{P} \%$ \\
\hline baseline & 66 & 100,00 & 0,00 & 0 & 0,00 & 0,00 & 0 & 0,00 & 0,00 & 66 & 100 \\
\hline 12 month & 63 & 100,00 & 0,00 & 0 & 0,00 & 0,00 & 0 & 0,00 & 0,00 & 63 & 100 \\
\hline
\end{tabular}

\begin{tabular}{|c|c|c|c|c|c|c|c|c|c|c|c|}
\hline \multirow{3}{*}{ Time } & \multicolumn{11}{|c|}{ contact point } \\
\hline & \multicolumn{3}{|c|}{ alfa } & \multicolumn{3}{|c|}{ bravo } & \multicolumn{3}{|c|}{ charlie } & \multicolumn{2}{|c|}{ Total } \\
\hline & $\mathrm{N}$ & $\mathrm{P} \%$ & $\mathrm{Sp} \%$ & $\mathrm{~N}$ & $\mathrm{P} \%$ & Sp \% & $\mathrm{N}$ & $\mathrm{P} \%$ & $\mathrm{Sp} \%$ & $\mathrm{~N}$ & $\mathrm{P} \%$ \\
\hline baseline & 66 & 100,00 & 0,00 & 0 & 0,00 & 0,00 & 0 & 0,00 & 0,00 & 66 & 100 \\
\hline 12 month & 61 & 96,83 & 17,53 & 2 & 3,17 & 17,53 & 0 & 0,00 & 0,00 & 63 & 100 \\
\hline
\end{tabular}

$$
\chi 2=2,13 \mathrm{p}>0,05
$$

\begin{tabular}{|c|c|c|c|c|c|c|c|c|c|c|c|}
\hline \multirow{3}{*}{ Time } & \multicolumn{11}{|c|}{ changes in interdental papilla } \\
\hline & \multicolumn{3}{|c|}{ alfa } & \multicolumn{3}{|c|}{ bravo } & \multicolumn{3}{|c|}{ charlie } & \multicolumn{2}{|c|}{ Total } \\
\hline & $\mathrm{N}$ & $\mathrm{P} \%$ & $\mathrm{Sp} \%$ & $\mathrm{~N}$ & $\mathrm{P} \%$ & $\mathrm{Sp} \%$ & $\mathrm{~N}$ & $\mathrm{P} \%$ & $\mathrm{Sp} \%$ & $\mathrm{~N}$ & $\mathrm{P} \%$ \\
\hline baseline & 66 & 100,00 & 0,00 & 0 & 0,00 & 0,00 & 0 & 0,00 & 0,00 & 66 & 100 \\
\hline 12 month & 61 & 96,83 & 17,53 & 2 & 3,17 & 17,53 & 0 & 0,00 & 0,00 & 63 & 100 \\
\hline
\end{tabular}

$$
\chi 2=3,1 \quad \mathrm{p}>0,05
$$

$$
\chi 2=2,18 \quad \mathrm{p}>0,05
$$

Only the criterion surface of the filling was found to have statistically significant difference $(p<0,05)$.

\section{DISCUSSION:}

Amalgam and composites are the most commonly used materials for restoration of distal teeth as the relative share of composites is increasing steadily. This is necessitated by the growing tend towards even greater demands of patients for aesthetic restorations of the distal segments of the dentition. There are also studies that show similar durability of composites and amalgams fillings in a prolonged period of observation ${ }^{9}$. It is a common opinion that the main problem with composites is the polymerizational shrinkage. As a consequence of this, is regarded the appearance of fissures, 
marginal staining, postoperative sensitivity and secondary caries. So far have been offered various approaches for the solution of this problem, but they are all connected with optimizing the size and saturation with inorganic fillers. The shrinkage is due to the dimetacrylate matrix- the essential component of all currently manufactured dental composites.

3M ESPE developed a new monomer system based on an opened cationic ring, as the goal is to be created a composite material with polymerizational shrinkage of less than $1 \%$, named siloran ${ }^{6,7}$. Currently for this material there is mainly laboratory and experimental studies. With the current study was conducted one of the first clinical tests of the material. This greatly restricts the ability to compare the obtained results to others.

The presence of statistically significant difference for the criterion "surface of filling" can be explained by the fact that assassement "alpha" is given to a surface smooth as a enamel. Maybe the evaluators were very critical in the evaluation, it is known that there is no material to replace all the qualities of the enamel and this especially applies for its smooth, polished surface.

The results from in vitro studies can give us some information about clinical behaviour of this material. Two of them compare the degree of bacterial adhesion to silorane and methacrylate based composite material ${ }^{10,11}$. The first one finds no statistically significant difference in adhesion of Candida albicans between test composites, including silorane, and the lowest is adhesion of ormocer and compomer. In the other study the subjects are different types Streptococus mutans, and for three of them lower adhesion to silorane, compared with other composites was reported.

On one hand this corresponds to the obtained in this study results for the criteria "secondary caries". There is no statistically significant difference 12 months compared to the begining, i.e. there are not favorable conditions for adhesion of Streptococus mutans and other microorganisms along the borders of the filling. On the other hand, the obtained statistically significant difference for the criterion "surface filling" implies there will be easier adhesion of microorganisms on the rough surface. It will be of interest to see the results of the control examinations for a longer period of observation.

In another in vitro examination ${ }^{12}$ has been registered a change in colour and surface of the silorane composite and four known dimetacrylate composites according to SIE-LAB colour scale. Disc-shaped samples that are subjected to an artificial light-induced aging with plasma lamp are used. Colour changes were measured at different time intervalsbeginning, 24, 48, 72, 120, 192 hours. Generally materials show decrease in $\mathrm{L}^{*}$ (white-black) and $\mathrm{a}^{*}$ (red-green) and the values of $b^{*}$ (blue-yellow) are increasing. A great exception is Filtek Silorane, where values of $a^{*}$ and $b^{*}$ remain the same. The change in $\mathrm{E}(\Delta \mathrm{E})$ for all materials is a linear function of time, as it is smallest for Filtek Silorane and Herculite XRV. The conclusion of the authors is that silorone composite is presented best in terms of stability of colour compared to dimetacrylate composites. These results are identical to the obtained by us estimates in clinical conditions for the criterion "right colour".

In a research analyzing the polymerizational stress, silorane shows smaller values than the dimetacrilate composites $^{13}$. Other authors compared the strength and modulus of elasticity of the silorane with dimetacrylate composites. There are not found any statistically significant differences in terms of the strength, while the modulus of elasticity of the silorane is slightly lower ${ }^{14}$. These indicatorspolymerization stress, modulus of elasticity, have a relation toward marginal adaptation, change of colour along the borders of the cavity and hence the development of secondary caries. For all of the three criteria we did not receive statistically significant difference. Since in silorane there is a lack of oxigen inhibited layer, this has motivated scientists to explore the bond between the separate layers in incremental layering of the material ${ }^{15}$. They concluded that the bond between the layers is slightly weaker that the one in the dimetacrylate composites. Whether this has any clinical impact is difficult to assess from the present study. Two other studies ${ }^{16,17}$ examine the hydrolitic stability of the silorane composites in organic liquid simulants and aqueous solution. The authors conclude that the stability and insolubility of silorane makes them suitable for use in conditions of the oral cavity.

Yesilyurt et al., test in laboratory conditions the effects of food on hardiness and flexural strength of the silorane and of three dimetacrylate composites ${ }^{18}$. In clinical setting these parameters would affect the fracture and abrasion resistence of the filling. Both studied parameters are not affected by the effect of food in silorane, while for the dimetacryle composites there is a significant decrease in both hardiness and flexural strength. This was confirmed from our clinical observation-there were no fractures and localized abrasion.

In another study is examined the relation between the type of martix (silorane and dimetacrylate), and the marginal leakage in vitro ${ }^{19}$. The results show that in silorane it is not observed any leakage, unlike the other group. In the present study are made and evaluated only fillings of silorane composite. It would be more indicating if for each patient are made two fillings- one with a composite with dimetacrylate base, and the other - with silorane. This maybe a subject of future studies.

\section{CONCLUSION:}

In the conditions of this study Filtek Silorane Low Shrink Posterior Restorativ performed well for an observation period of 12 months. 


\section{REFERENCES:}

1.Nash RW, Lowe RA, Leinfelder K. Using packable composites for direct posterior placement - J Am Dent Assoc. 2001 Aug;132(8):1099-104.

2.Manhart J, Kunzelmann KH, Chen HY, Hickel R. Mechanical properties and wear behaviour of light - cured packable composite resins - Dent Mater. 2000 Jan;16(1):33-40.

3.Tanagawa M, Yoshida K, Matsumoto $\mathrm{S}$, Yamada T, Atsuta M. Inhibitory effect of antibacterial resin composite against Streptoccocus mutans - Caries Res. 1999 Sep-Oct;33(5):366-71.

4. Cobb DS, MacGregor KM, Vargas MA, Denehy GE. The physical pro-perties of packable and conventional posterior resin - based composites: a comparison - J Am Dent Assoc. 2000 Nov;131(11):1610-5.

5. Kournetas N, Chakmakchi M, Kakaboura A, Rahiotis C, Geis-Gerstorfer J. Marginal and Internal adaptation of Class II ormocer and hybrid resin composite restorations before and after cycling - Clin Oral Investig. 2004 Sep;8(3):123-9.

6. Weinmann W., Thalacker Ch., Guggenberger R. Siloranes in dental composites - Dent Mater. 2005 Jan; 21(1): 68-74.

7. Schattenberg A. et al. Shrinkage stress of new experimental low shrinkage resin composites. IADR 2007, New Orleans, USA, Abstract \#0412

8. Brandenbusch M. et al. One year performance of an innovative silorane posterior composite. IADR 2007, New Orleans, USA, Abstract \#1581

9. Hickel R, Kaaden C, Paschos E, Buerkle V, Garcна-Godoy F, Manhart J. Longevity of occlusally-stressed restorations in posterior primary teeth. Am J Dent. 2005 Jun;18(3):198-211.

10. Buergers R, Schneider-Brachert W, Hahnel S, Rosentritt M, Handel G. Streptococcal adhesion to novel low-shrink silorane-based restorative. Dent Mater. 2009 Feb;25(2):269-75. Epub 2008 Sep 2.

11. Burgers R, Schneider-Brachert W, Rosentritt M, Handel G, Hahnel S. Candida albicans adhesion to composite resin materials. Clin Oral Investig. 2009 Sep;13(3):293-9. Epub 2008 Sep 23.

12. Furuse AY, Gordon K, Rodrigues FP, Silikas N, Watts DC. Colour-stability and gloss-retention of silorane and dimethacrylate composites with accelerated aging. J Dent. 2008 Nov;36(11):945-52. Epub 2008 Sep 7.

13. Eick JD, Kotha SP, Chappelow CC, Kilway KV, Giese GJ, Glaros AG, Pinzino CS. Properties of silorane-based dental resins and composites containing a stressreducing monomer. Dent Mater. 2007 Aug;23(8):1011-7. Epub 2006 Nov 9.

14. Ilie N, Hickel R Silorane-based dental composite: behavior and abilities. Dent Mater J. 2006 Sep;25(3):445-54

15. Tezvergil-Mutluay A, Lassila LV, Vallittu PK. Incremental layers bonding of silorane composite: The initial bonding properties. J Dent. 2008 Jul;36(7):560-3

16. Palin WM, Fleming GJ, Burke FJ, Marquis PM, Randall RC. The influence of short and medium-term water immersion on the hydrolytic stability of novel lowshrink dental composites. Dent Mater. 2005 Sep;21(9):852-63. [PubMed]

17. Eick JD, Smith RE, Pinzino CS, Kostoryz EL. Stability of silorane dental monomers in aqueous systems. J Dent. 2006 Jul;34(6):405-10

18. Yesilyurt C, Yoldas O, Altintas SH, Kusgoz A. Effects of food-simulating liquids on the mechanical properties of a silorane-based dental composite. Dent. Mater. J. 2009 May;28(3):362-7. [PubMed]

19. Bagis YH, Baltacioglu IH, Kahyaogullari S. Comparing Microleakage and the Layering Methods of Siloranebased Resin Composite in Wide Class II MOD Cavitiies. Oper Dent. 2009 SepOct;34(5):578-85.

\author{
Address for correspondence: \\ Dr. Lyubomir Vangelov \\ Department of Operative Dentistry and endodontics, Faculty of dental medicine, \\ Merical University Plovdiv \\ 3, Hristo Botev bul., Plovdiv, Bulgaria \\ tel.: +359/887495325 \\ e-mail: lubovangelov@mail.bg
}

